\title{
DINÂMICA DO DESMATAMENTO EM ÁREA DE ASSENTAMENTO DE REFORMA AGRÁRIA NO SUDESTE PARAENSE
}

\author{
Ismael Alves Amorim \\ Universidade do Estado do Pará \\ Mestrando do Programa de Pós-Graduação em Ciências Ambientais - PPGCA \\ ismaelamorim93@gmail.com \\ Andréa Hentz de Mello \\ Professora da Universidade Federal do Sul e Sudeste do Pará \\ Programa de Pós-Graduação em Dinâmicas Territoriais e Sociedade na Amazônia - PDTSA \\ andreahentz@unifesspa.edu.br \\ Alfredo Kingo Oyama Homma \\ Pesquisador da Embrapa Amazônia Oriental \\ Professor da Universidade do Estado do Pará \\ alfredo.homma@embrapa.br \\ Altem Nascimento Pontes \\ Professor da Universidade do Estado do Pará \\ Programa de Pós-Graduação em Ciências Ambientais - PPGCA \\ altempontes@hotmail.com
}

\begin{abstract}
RESUMO:
O Sudeste Paraense é uma região que foi alvo das medidas de integração da Amazônia ao núcleo econômico e político do país e dentre essas medidas está a reforma agrária, realizada com base na criação de assentamentos em áreas desapropriadas. Porém, o descaso e a falta de planejamento com esse processo de colonização resultaram em altos índices de desflorestamento ao longo do tempo, colocando os assentamentos no foco das atuais discussões sobre o desmatamento na Amazônia. Neste sentido, objetivou-se com este trabalho avaliar a dinâmica do desmatamento e suas relações com o contexto histórico e agrário no Projeto de Assentamento 26 de Março, em um universo temporal entre 1990 a 2019. Para a consolidação dos objetivos foram utilizados dados de sensoriamento remoto e Sistemas de Informações Geográficas - SIG para o processamento dos dados e confecção de produtos cartográficos. Os resultados mostraram que a área de floresta do assentamento foi suprimida em $50 \%$, dando lugar, sobretudo, as atividades agropecuárias, representando em 2019, mais que $65 \%$ do total da área de estudo. Assim, ressalta-se a necessidade do fortalecimento de políticas públicas adequadas à realidade do assentamento, bem como a geração, difusão e acesso a alternativas de produção sustentáveis.
\end{abstract}

Palavras-chave: Amazônia. Pequena produção. Políticas públicas.

\section{DEFORESTATION DYNAMICS IN THE AGRARIAN REFORM SETTLEMENT AREA IN SOUTHEASTERN PARAENSE}

\begin{abstract}
Southeast Paraense is a region that was the target of measures to integrate the Amazon into the country's economic and political nucleus and among these measures is land reform, carried out based on the creation of settlements in expropriated areas. However, the neglect and lack of planning with this colonization process resulted in high rates of deforestation over time, placing the settlements at the center of current discussions on deforestation in the Amazon. In this sense, the objective of this work was to evaluate the dynamics of deforestation and its relations with the historical and agrarian context in the Settlement Project 26 de Março, in a time universe between 1990 to 2019. To consolidate the objectives, data from sensing were used remote and Geographic Information Systems - GIS for data processing and making cartographic products. The results showed that the settlement's forest area was suppressed by $50 \%$, giving rise, above all, to agricultural
\end{abstract}

$\begin{array}{lllll}\text { Caminhos de Geografia } \quad \text { Uberlândia-MG } & \text { v. 21, n. } 78 & \text { Dez/2020 } & \text { p. 21-35 } & \text { Página } 21\end{array}$


activities, representing in 2019 more than $65 \%$ of the total study area. Thus, the need to strengthen public policies appropriate to the reality of the settlement is highlighted, as well as the generation, dissemination and access to sustainable production alternatives.

Keywords: Amazon. Small production. Public policy.

\section{INTRODUÇÃO}

O desmatamento na mesorregião do Sudeste Paraense é fruto de um processo histórico que está intimamente relacionado com a política de colonização e ocupação da região e nesse cenário estão os assentamentos de reforma agrária criados pelo Instituto Nacional de Colonização e Reforma Agrária INCRA (LEAL e MANIESE, 2018). Atualmente os assentamentos estão no foco das discussões sobre desmatamento no Sudeste Paraense, uma vez que houve mudanças no padrão de desfloramento e taxas crescentes de pequenas derrubadas florestais são percebidas, decorrentes das atividades desenvolvidas pelos agricultores familiares, por isso é necessário investigar a relação existente entre desmatamento e a política de reforma agrária (FARIAS et al., 2018a; ÁVILA et al., 2018).

Carvalho e Domingues (2016) afirmam que a região amazônica vem sendo explorada desde o período colonial, mas foi na década de 1960 que o governo brasileiro decidiu reduzir o "vazio demográfico" e integrar a Amazônia à economia brasileira, por meio de grandes projetos de integração responsáveis por atrair um significativo contingente populacional de outras regiões do país. Assim foi promovido, de maneira desordenada, o deslocamento de grupos sociais de áreas com maior concentração populacional e maior índice de conflito agrário, para as áreas pouco povoadas da Amazônia (JOANONI NETO; GUIMARÃES NETO, 2019).

A construção de infraestruturas como rodovias, ferrovias, Usina Hidrelétrica de Tucuruí, a implantação do Programa Grande Carajás, fazem parte de políticas mais incisivas de desenvolvimento regional, tendo as suas consequentes formas de ordenamento territorial para a Amazônia e para o Sudeste Paraense (TRINDADE JÚNIOR; MADEIRA, 2016). Devido aos incentivos fiscais e a lucratividade associada aos baixos preços da terra, também ocorreu o processo de pecuarização do Sudeste Paraense, principal vetor do crescimento na região, o que resultou em uma rápida e drástica mudança na paisagem, compondo gradativamente um imenso mosaico rural (NASCIMENTO et al., 2015).

Todo esse processo de ocupação provocou sérios problemas ambientais, estimulando a conversão das florestas e intensificando a transformação da paisagem local em uma nova dinâmica de uso e cobertura do solo como forma de consolidação da terra (ZAMBONIN et al., 2017). Assim, o Sudeste Paraense começou a atingir elevados índices de desmatamento que foram se agravando com o passar do tempo e com o aumento das atividades pouco sustentáveis, tal fato desencadeou uma série de outros impactos das mais diversas ordens nos recursos naturais, tendo a pecuária como principal atividade responsável pela conversão da floresta em usos distintos (CÔRTES e D'ANTONA, 2014).

Segundo Pereira (2015), outra política importante que se relaciona a esse contexto é a reforma agrária, que define a propriedade rural como local para se cumprir a "função social da terra", estando de acordo a legislação trabalhista e exploração que favoreça o bem-estar dos trabalhadores agrícolas. Nesse sentido, o Sudeste Paraense tem sido alvo de uma sucessão de políticas de reforma agrária com a criação de diversos assentamentos em áreas desapropriadas (INCRA, 2017). Esses assentamentos são importantes para distribuição de terras e são compostos principalmente de agricultores sem-terra do Nordeste e Sudeste do país que praticam atividades agropecuárias e fazem da terra sua fonte de sobrevivência (ALVES e BISPO, 2018; YANAl et al., 2016).

Farias et al. (2018b) colocam a reforma agrária como uma política que provoca o desmatamento, uma vez que o processo de colonização da Amazônia sempre esteve relacionado ao ato de desmatar como forma explorativa e para demonstrar posse da terra, por parte dos colonos. Em contrapartida, Sangalli et al. (2014) afirmam que a reforma agrária é resultado de um processo social e econômico com possibilidades de desenvolvimento rural, aliando políticas públicas com a produção de alimentos de forma sustentável e fortalecendo a pequena produção, sendo o Sudeste Paraense uma região bem característica dessa conjuntura.

A pequena produção caracteriza-se quando a família é simultaneamente a proprietária dos meios de produção e assume o trabalho nas unidades produtivas, sendo que as técnicas utilizadas são definidas 
pelos próprios agricultores, os quais se utilizam de seus conhecimentos tradicionais em todas as fases do processo (MACIEL, 2014). Assim, Alencar et al. (2016) afirmam que o estudo do desmatamento nos assentamentos de pequenos produtores do Sudeste Paraense, mostra-se como ferramenta fundamental para descoberta e compreensão dos motivos que impulsionam a degradação ambiental nesses locais, sendo necessário investigar o contexto da implantação do assentamento e a forma como se deu a consolidação dos assentados.

Neste contexto, o objetivo deste trabalho foi avaliar a dinâmica do desmatamento e suas relações com o contexto histórico e agrário no Projeto de Assentamento 26 de Março, município de Marabá, em um universo temporal entre 1990 a 2019.

\section{Pequena produção, assentamentos e desmatamento no Sudeste Paraense}

De acordo com Bittencourt e Bianchini (1996), a pequena produção é definida como uma unidade que tem sua fonte de renda superior a $80 \%$ oriundo da agricultura e que a força de trabalho empregada na propriedade seja igual ou superior a 75\% resultante da própria família. Segundo a Lei n. 11.326 de 24 de julho de 2006, consideram-se como características do agricultor familiar, que os mesmos não possuam área maior que quatro módulos fiscais, com predomínio da mão-de-obra da própria família com renda familiar predominantemente vinculada com a sua propriedade e que a gestão seja exercida pela própria família (MDA, 2018).

A pequena produção é de extrema importância na questão da segurança alimentar do país, os alimentos produzidos nas pequenas propriedades fazem parte em sua grande maioria da alimentação básica do brasileiro (OLIVEIRA e PEREIRA, 2010). Segundo Sangalli et al. (2014), a pequena produção se adapta a diferentes realidades sociais, econômicas e políticas, e neste contexto figuram os assentamentos de reforma agrária de pequenos produtores, resultantes de um processo social e econômico com possibilidades de desenvolvimento rural, aliando políticas públicas com a produção de alimentos de forma sustentável.

Em síntese, os projetos de assentamentos criados pelo INCRA estão dentre as políticas públicas que visam promover a reforma agrária e o desenvolvimento rural e sustentável, tendo como grande objetivo a promoção do desenvolvimento rural por meio da pequena produção e mesmo nos piores casos, revelam a importância da distribuição de terras como uma possibilidade de inclusão e transformação social (HORA et al., 2019). Partindo deste pressuposto, o processo de produção do espaço nos assentamentos, se dá através do uso dos recursos naturais pelo homem para sua sobrevivência e da sociedade, adicionando ou retirando elementos da natureza através do trabalho e consequentemente modificando a paisagem (ALENCAR, 2017).

No Brasil, o Pará é o estado que mais possui projetos de assentamentos de reforma agrária, tendo um grande destaque, neste contexto, o Sudeste Paraense, que é marcado pela presença efetiva e consolidada de grande número de pequenos produtores que vivem nestes assentamentos e produzem alimentos para o seu próprio consumo e dos centros urbanos próximos, evidenciando a importância social e econômica dos assentamentos e da pequena produção para esta região (INCRA, 2017).

Ainda segundo o INCRA (2017), na Superintendência de Marabá (SR-27) que contempla em grande parte o Sudeste Paraense, existem atualmente 514 projetos de assentamentos, com mais de 72 mil famílias, abrangendo uma superfície de mais 4 milhões de hectares, constituída de pequenos produtores, posseiros, integrantes do Movimento dos Trabalhadores Rurais Sem Terra (MST), que chegaram a região em busca de melhores condições de vida, fugindo da exclusão social de outras regiões do país.

De acordo com Leite et al. (2014), grande parte da pesquisa sobre o desmatamento em assentamentos de reforma agrária no Brasil tem sido realizada na Amazônia, principalmente porque é nessa região que o número de assentamentos é mais predominante, e tais pesquisas apontam para o aumento das taxas de desmatamento e de diversos outros efeitos correlacionados como erosão dos solos e perda de biodiversidade, processos que comprometem a sustentabilidade da pequena produção, principalmente no Sudeste Paraense.

Neste mesmo contexto, Vieira et al. (2014) afirmam que nos assentamentos de reforma agrária do Sudeste Paraense, a ocorrência do desmatamento está associada à prática agropecuária de corte e à queima de florestas e vegetação secundária, que ainda é a principal forma de preparo de áreas agrícolas usadas por agricultores familiares para a produção de alimentos e geração de renda para suas famílias, além disso, diversos outros atores sociais, como madeireiros e grandes fazendeiros, estão associados ao desmatamento em áreas de assentamentos de reforma agrária na região. 
Nessa área, as consequências ambientais são preocupantes, desde a perda da própria floresta até a instalação e consolidação dos processos de erosão do solo, tais impactos não deixam dúvidas de que a falta de controle e planejamento ambiental tem sido um dos fatores decisivos para as atividades não florestais, cujo ritmo se modifica claramente em função dos sistemas de produção, principalmente para a implantação da pecuária, que ocupa grandes extensões de terra (SAMPAIO et al., 2003).

Diante desta situação torna-se imprescindível a intervenção do homem sobre o meio natural, pois devido à falta de alternativas tecnológicas e infraestrutura adequadas os agricultores procuram uma estratégia que garanta em curto prazo um retorno econômico, encontrando na conversão da floresta a satisfação desta necessidade, assim muitas áreas de floresta densa são dizimadas (ZAMBONIN, 2017).

Para Soares e Espindola (2008), é importante o planejamento na organização do espaço interno dos projetos de assentamentos rurais no Sudeste Paraense para se evitar problemas com o uso da terra, de modo que os modelos de estruturação fundiária emanem das peculiaridades socioculturais, infraestruturas e ambientais da região, condicionante para êxito das iniciativas promotoras do desenvolvimento rural sustentável.

\section{CONTEXTO HISTÓRICO DO PROJETO DE ASSENTAMENTO 26 MARÇO}

O Projeto de Assentamento 26 de Março é um dos mais conhecidos do Sudeste Paraense, seja por seu contexto histórico, marcado por toda uma fase de exploração dos recursos naturais ou pelas suas características atuais, sendo símbolo da resistência incisiva e insistente do MST para com o processo de reforma agrária, sendo o seu nome, uma alusão à data da ocupação da fazenda que deu origem ao assentamento pelos integrantes do MST, que ocorreu em 26 de março de 1999 (EMATER, 2013).

O contexto histórico do assentamento está diretamente ligado aos ciclos econômicos extrativos ocorridos na Amazônia, o da borracha e o da castanha, sendo este último bastante presente na história do Sudeste Paraense e do próprio assentamento (BARROS, 2011). Aliado a isso também está à conjuntura de transição da economia do Sudeste Paraense para mineração e agropecuária, bem como as políticas de colonização, regularização e legalização fundiárias encabeçadas pelo INCRA (BARREIROS et al., 2017).

Neste sentido é importante destacar como se deu a construção do processo histórico referente ao Projeto de Assentamento 26 de Março, desde a época em que a área do mesmo era conhecida como Castanhal Cabaceiras e fazia parte do intricado sistema de oligopólio dos castanhais até ser destinada à reforma agrária.

Até os anos 20 do século passado, a exploração dos castanhais no Sudeste Paraense era realizada de forma livre, mas a partir do momento em que a castanha se transforma em fonte de troca e provedora de lucros, inicia-se o processo de cercamento dos castanhais, isto é, os acessos às áreas de ouriços que antes eram livres, passam a ser realizados mediante arrendamento (BARROS, 2011). Ainda segundo esse autor, os donos dos castanhais passam a ser os grupos de famílias que também controlavam a estrutura comercial da época, como transportes, gêneros alimentícios e escoamento da produção de castanha, e dessa forma concentravam terras e poder constituindo-se como verdadeiras oligarquias.

A partir de 1989, com o poder e capital advindo da oligarquia dos castanhais, ocorre aquisição da Fazenda Castanhal Cabaceiras, uma extensa área rica em castanhais localizada nas proximidades do Município de Marabá e no auge da economia castanheira essa área fora uma das maiores exportadoras de castanha no município de Marabá e no estado do Pará (IFPA, 2012).

Entre 1960 e 1970, com o processo de colonização e exploração do Sudeste Paraense em ritmo mais intenso e acelerado, ocorreu a consolidação de um novo uso da terra, fato que acarretou a partir de então, a transição de uma economia baseada no extrativismo, controlada por grupos de famílias com poder e capital, para uma economia industrial exportadora baseada na exploração mineral e na pecuária de corte com destaque ao fomento governamental para essas atividades (NEVES e SCHMITZ, 2018).

A partir desses acontecimentos, iniciou-se então a derrubada da cobertura florestal nas áreas de castanhais em razão das atividades madeireiras e agropecuárias, incentivadas pela fronteira agrícola e na Fazenda Castanhal Cabaceiras não foi diferente. Com a decisão de desmatar as áreas de castanhais para a produção agropecuária e madeireira, é inaugurada uma nova fase no ciclo de apropriação, uso e transformação da terra diante de um novo contexto econômico em Marabá, o da pecuária (EMMI, 2002).

Nessa nova conjuntura regional, a Fazenda Castanhal Cabaceiras foi dedicada às atividades pecuárias por mais de uma década, sendo considerada uma propriedade modelo na produção extensiva de bovinos

$\begin{array}{lllll}\text { Caminhos de Geografia } \quad \text { Uberlândia-MG } & \text { v. 21, n. } 78 & \text { Dez/2020 } & \text { p. 21-35 } & \text { Página } 24\end{array}$ 
para corte, mas partir de 1999 esse quadro muda drasticamente, quando sob suspeita da fazenda ter sido adquirida por meio de documentos fraudulentos e irregulares, a chamada grilagem de terra, ocorre à ocupação da fazenda por integrantes do MST que reivindicavam a desapropriação da área para fins de reforma agrária (BARROS, 2011).

A ocupação da Fazenda Cabaceiras se deu no dia 26 de março de 1999 e um dos principais objetivos do MST era enfraquecer a oligarquia agrária regional e a família que tinha a posse das terras e que era vista como a mais forte na região na concentração de latifúndios, dessa forma, as reivindicações do MST eram pela desapropriação por suspeita de grilagem, como já mencionado, mas com toda a documentação da cadeia dominial dos títulos da área, ficou provado que a fazenda foi apropriada de forma legal, por isso o argumento do movimento sem-terra foi invalidado (GAMA, 2016; BARROS, 2011).

Com a ocupação da fazenda, houve o surgimento de diversas denúncias da existência de trabalho análogo ao escravo durante todo processo de conversão florestal praticado na Fazenda Cabaceiras, fato que culminou com a abertura de um processo administrativo no INCRA para apurar as denúncias e com isso foram realizadas diversas vistorias pelo INCRA e IBAMA para avaliação do cumprimento ou não da função social da terra na fazenda, visto que as acusações violavam a legislação assegurada pela Lei №4.504 de 1964 (FREITAS, 2009). Em muitas das vistorias foi constatado que existiam irregularidades nas relações e condições de trabalho da fazenda e também um grande passivo ambiental instalado, com extensas áreas desmatadas.

Assim, em 2008, a Justiça Federal decidiu em favor do INCRA, dando posse da fazenda para o órgão Federal e em 19 de dezembro do mesmo ano realizou-se oficialmente 0 ato de desapropriação da Fazenda Cabaceiras e a criação do Projeto de Assentamento 26 de Março (ARAÚJO, 2008). Esse autor ainda ressalta que a desapropriação da Fazenda Cabaceiras para criação do assentamento foi caracterizada como um marco histórico no contexto agrário do Brasil, uma vez que foi o primeiro latifúndio desapropriado por incidência de crimes ambientais e trabalho escravo.

Atualmente, residem no assentamento 205 famílias e mesmo com a predominância da pastagem, devido aos antecedentes históricos de uso da área, as famílias tentam construir sistemas produtivos diversificados combinando agricultura e pecuária, além do extrativismo (EMATER, 2013; INCRA, 2017).

\section{MÉTODO}

\section{Caracterização da área de estudo}

A área de estudo está localizada no município de Marabá, na mesorregião do Sudeste Paraense. Sendo uma cidade média amazônica, o respectivo município é o quarto mais populoso do estado do Pará e o mais populoso do Sudeste Paraense, contando atualmente com 283 mil habitantes e com um dos processos de ocupação mais antigos. Possui como modelo econômico de exploração dominante a mineração e a criação extensiva de bovinos nas áreas de pastagens do município (IBGE, 2020; MENGATTO JÚNIOR, 2017).

O Projeto de Assentamento 26 de Março, objeto de estudo deste trabalho, possui uma área aproximada de 10.260,000 ha e situa-se a $25 \mathrm{~km}$ da sede do município de Marabá (Figura 1), podendo ser acessado pela BR-155, que liga Marabá a Eldorado do Carajás e corta a área na direção norte-sul.

O assentamento está inserido na região conhecida como Polígono dos Castanhais, uma área de terra localizada no Sudeste do Pará com aproximadamente 1.694 .568 ha, caracterizada por uma grande concentração de castanheiras (Bertholletia excelsa) (PEREIRA, 2015). Essa região foi muito importante no contexto histórico de ocupação e exploração dos recursos naturais e além de Marabá, o Polígono dos Castanhais abrange o município de Eldorado do Carajás, e em menor proporção, os municípios de Bom Jesus do Tocantins, Itupiranga, Curionópolis, São Domingos do Araguaia, São Geraldo do Araguaia, São João do Araguaia, Piçarra e Xinguara (BRINGEL, 2015).

Em relação ao clima, segundo Köppen, o clima da microrregião de Marabá, onde está localizado o Projeto de Assentamento 26 de Março, é quente úmido com temperatura anual de $27,5^{\circ} \mathrm{C}$, com precipitação pluvial total de $1.746 \mathrm{~mm}$, no qual 75\% das precipitações ocorrem entre dezembro e abril (INMET, 2019). $\mathrm{O}$ relevo do local varia de plano a suavemente ondulado, com alguns poucos locais com topografia ondulada. Na questão da hidrografia, a região pertence à bacia hidrográfica do Araguaia-Tocantins, 
Dinâmica do desmatamento em área de assentamento de reforma agrária no Sudeste Paraense
Ismael Alves Amorim

Andréa Hentz de Mello

Alfredo Kingo Oyama Homma Altem Nascimento Pontes

ficando próximo da região do médio Rio Tocantins e em relação à hidrografia da área de estudo, o Rio Sororó, afluente do Rio Itacaíunas, apresenta-se como o principal curso de água presente e constitui-se como o limite no sentido oeste do assentamento (EMATER, 2013).

Figura 1 - Localização do Projeto de Assentamento 26 de Março, munícipio de Marabá, Sudeste Paraense.

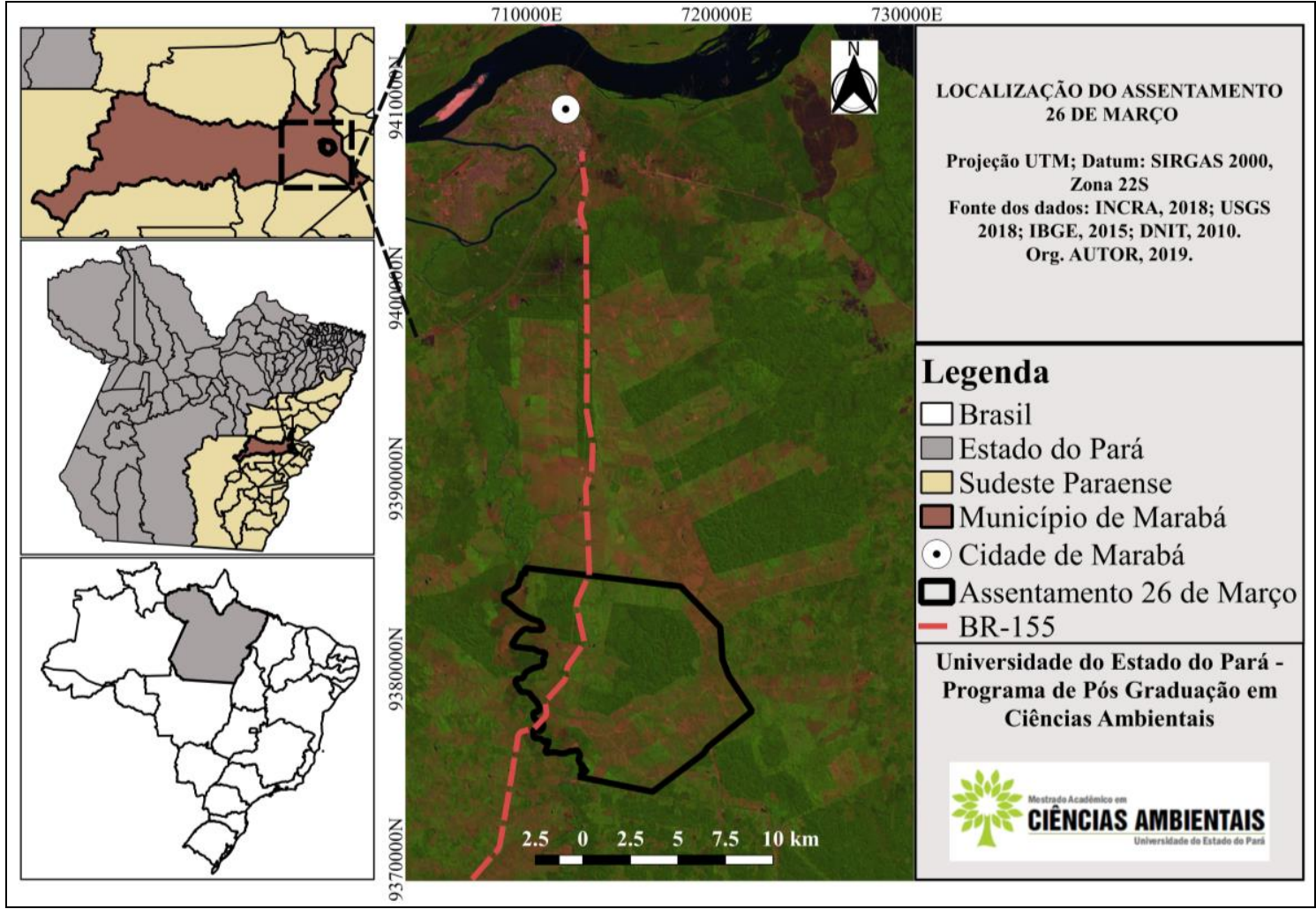

Fonte - INCRA, 2018; USGS, 2018; IBGE, 2015; DNIT, 2010; Org. AUTOR.

\section{Organização dos dados}

Nessa etapa do trabalho foi realizada a organização e sistematização das bases de dados. Neste sentido para a caracterização do uso e cobertura da terra na área do Projeto de Assentamento 26 de Março, foram utilizadas imagens do satélite Landsat (órbita ponto: 223-06), bandas TM 3, 4 e 5 (Landsat 5) e bandas TM 6, 5 e 4 (Landsat 8) obtidas de forma gratuita da base de dados do site do USGS (Serviço Geológico dos Estados Unidos).

O estudo do desmatamento foi realizado em três momentos apontados neste estudo como fundamentais para entender a dinâmica da paisagem no Projeto de Assentamento 26 de Março. As análises foram realizadas com base em imagens de satélite dos anos de 1990, 2005, 2019, com um intervalo de aproximadamente 15 anos entre as amostragens, conforme descrito na Tabela 1. Esse intervalo entre as avaliações é importante para se observar mudanças na paisagem quando se trabalha com cobertura vegetal (VARANDA et al., 2018).

Tabela 1 - Data de aquisição das imagens de satélite pelos sensores TM e OLI no Landsat (órbita ponto: 223-06).

\begin{tabular}{ccc}
\hline $\begin{array}{c}\text { Data de aquisição da imagem } \\
\text { pelo sensor }\end{array}$ & Sensor/Instrumento & Bandas espectrais \\
\hline 10 de junho de 1990 & TM/Landsat 5 & TM3, TM4, TM5 \\
08 de junho de 2005 & TM/Landsat 5 & TM3, TM4, TM5 \\
13 de agosto 2019 & OLI/Landsat 8 & TM4, TM5, TM6 \\
\hline
\end{tabular}

Fonte - USGS. Org. AUTOR. 


\section{Processamento dos dados}

A análise dos dados foi conduzida no Sistema de Processamento de Informações Georreferenciadas (SPRING - versão 5.5.2). Em cada imagem foi realizado o recorte com base no arquivo shapefile do assentamento fornecido pelo INCRA SR-27. No passo seguinte foram feitas as composições coloridas TM 5R4G3B (Landsat 5) e 6R5G4B (Landsat 8). Depois do processo de combinação das bandas executado, os resultados foram novas imagens coloridas em formato GEOTIFF. Posteriormente, aplicou-se a Ampliação Linear de Contraste, para facilitar a interpretação das informações nelas contidas, uma vez que, é a partir dessa imagem que foi realizado o processo de classificação.

Foram executadas classificações supervisionadas por falsa cor, pelo método da máxima verossimilhança (MAXVER), caracterizado como do tipo "pixel a pixel", porque utiliza apenas a informação espectral, isoladamente, de cada pixel para encontrar regiões homogêneas, considerando a ponderação das distâncias entre médias dos níveis digitais das classes, utilizando parâmetros estatísticos (INPE, 2017).

Para o processo de classificação no SPRING, segue-se as seguintes etapas, conforme a Figura 2:

- Treinamento: Coleta de amostras na imagem de satélite e avaliação do desempenho das mesmas, a partir da análise individual de cada classe e suas respectivas amostras e geração da matriz de confusão;

- Classificação: Processamento e classificação propriamente dita da imagem e geração das classes trabalhadas na análise de desmatamento, com um limiar de aceitação de 99,9\%;

- Pós-classificação: Refinamento e ajustes dos produtos gerados na fase de classificação. É nessa fase que pequenos erros são corrigidos para maior confiabilidade nos resultados;

- Mapeamento: Edições temáticas finais nos mapas gerados, onde se escolheu a cor das classes, e se fez o cálculo da área de cada classe, em hectares, pela função "Medida de Classes".

Figura 2 - Diagrama com a descrição das etapas do processo de classificação supervisionada por falsa cor no software SPRING.

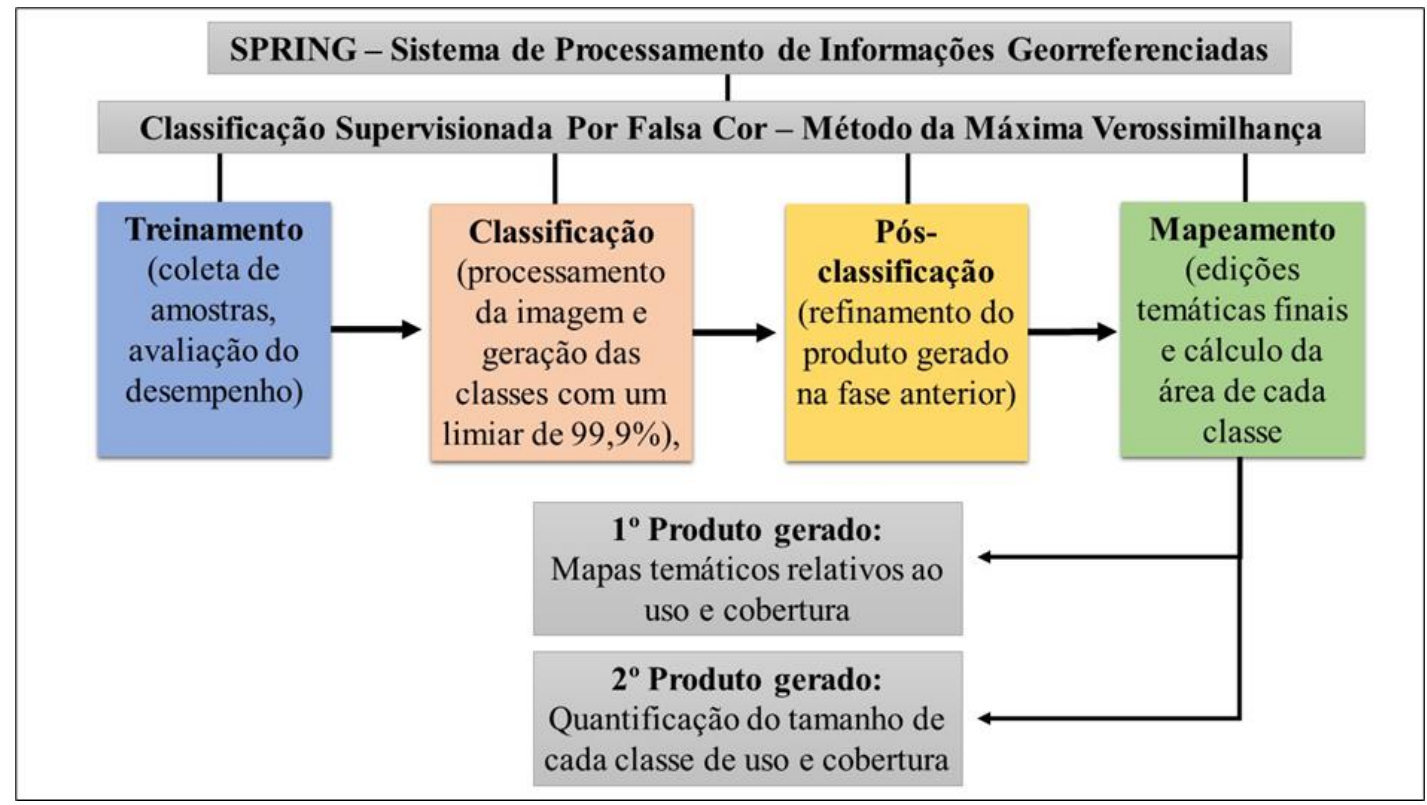

Fonte - INPE. Org. AUTOR.

Os produtos gerados ao final do processo de classificação foram mapas temáticos relativo ao uso e cobertura da terra para cada ano de análise, com informações do tamanho de cada classe de uso e cobertura em arquivo txt. Após a conclusão da classificação, os mapas foram exportados para o software QGIS (versão 2.18) para a elaboração do layout do mapa. Os dados referentes ao tamanho das classes gerados em formato txt foram exportados para o Microsoft Excel em forma de tabela. Por fim, os 
resultados encontrados foram interpretados e relacionados a acontecimentos específicos no contexto histórico e agrário do local e que remetem de alguma forma a dinâmica do desmatamento ao longo do período estudado.

\section{Classes de uso e cobertura utilizadas}

Para interpretação das imagens de satélite referentes ao processo de desmatamento foram utilizadas duas classes, floresta e agropecuária, conforme caracterização descrita no Quadro 1, baseadas em trabalhos de Loebmann et al. (2012) e Pinto (2016):

Quadro 1 - Caracterização das classes utilizadas na dinâmica do desmatamento no Projeto de Assentamento 26 de Março.

\begin{tabular}{|l|l|}
\hline \multicolumn{1}{|c|}{ CLASSE } & \multicolumn{1}{c|}{ CARACTERISTICAS } \\
\hline Floresta & $\begin{array}{l}\text { Conjunto denso de árvores que cobrem de forma contínua ou não, determinada } \\
\text { proporção solo. Compreendem as áreas de formações florestais de diversos tipos, } \\
\text { podendo ser das categorias abertas ou fechadas, matas ciliares ou de galeria e reserva } \\
\text { legal, ou até mesmo as floretas secundárias. Por geralmente serem organismos de } \\
\text { grande porte e que formam dossel, são facilmente detectáveis nas imagens de satélite } \\
\text { por conta da coloração e de sua resposta espectral, que se apresenta em tons de verde, } \\
\text { com uma textura rugosa ou não. }\end{array}$ \\
\hline Agropecuária & $\begin{array}{l}\text { Fazem parte dessa classe, pastagens em processo produtivo, com predomínio de } \\
\text { vegetação herbácea, ausência arbórea e baixa infestação por invasoras herbáceas e } \\
\text { arbustivas. Pastagens que apresentam diferentes estágios de degradação com presença } \\
\text { significativa de vegetação arbustiva esparsa e poucos indivíduos arbóreos. Ainda se } \\
\text { incluem nessa classe os cultivos anuais, perenes e semiperenes. Essa classe compõe } \\
\text { em grande parte o sistema produtivo do assentamento, representando fonte de renda e } \\
\text { alimento para as famílias. }\end{array}$ \\
\hline
\end{tabular}

Fonte - (LOEBMANN et al., 2012; PINTO, 2016).

\section{RESULTADOS E DISCUSSÃO}

Os resultados referentes à dinâmica do desmatamento no Projeto de Assentamento 26 de Março, levantados durante o período estudado são apresentados de forma quantitativa na Tabela 2, trabalhandose a área em hectares e porcentagem e também são espacializados nos mapas temáticos conforme Figuras 3 e 4, para possibilitar a geovisualização dos produtos gerados no processo de classificação.

Conforme pode ser visto na Tabela 2, a área de floresta da paisagem em questão sofreu uma supressão considerável de sua vegetação, sobretudo no período entre 1990 (Figura 3A) e 2005 (Figura 3B), que representa a primeira metade do período avaliado, sendo marcado pelo desmatamento das áreas de castanhais nativos existentes na ainda Fazenda Cabaceiras, para implantação de pastagens e posterior consolidação da pecuária como atividade rural predominante. As atividades agropecuárias (nesse período resumidas em pastagens) que em 1990 constituíam apenas $20 \%$ do total da área, na análise seguinte já representavam aproximadamente $60 \%$ da área total.

Tabela 2 - Quantificação do desmatamento na área do Projeto de Assentamento 26 de Março no período de 1990 a 2019.

\begin{tabular}{ccccccc}
\hline & \multicolumn{2}{c}{1990} & \multicolumn{2}{c}{2005} & \multicolumn{2}{c}{$\mathbf{2 0 1 9}$} \\
\cline { 2 - 7 } CLASSES & ha & $\%$ & ha & $\%$ & ha & $\%$ \\
\hline Floresta & $8.201,00$ & 80 & 4.257 & 41 & $3.264,00$ & 32 \\
Agropecuária & 2.059 & 20 & 6.003 & 59 & 6.996 & 68 \\
\hline Total & $10.260,00$ & 100,00 & $10.260,00$ & 100,00 & $10.260,00$ & 100 \\
\hline
\end{tabular}


Segundo Barros (2011), até o ano de 1989 e 1990, a atividade principal da Fazenda Cabaceiras era o extrativismo da castanha, no entanto, no período seguinte, torna-se intensa a derrubada da mata com destinação da madeira ao comércio de exportação. Mais tarde inicia-se um processo mais consolidado de transformação da paisagem que é o desmatamento de grandes áreas de floresta nativa e sua posterior conversão em pastagem, para a criação de gado de alta produtividade e genética apurada, que ocorre a partir da década de 1990. Segundo Scole et al. (2016), no Sudeste Paraense foi observado que os castanhais de Bertholletia excelsa foram substituídos por pastagem, sendo ainda encontrados remanescentes desta formação vegetal natural.

Figura 3 - Mapa temático de desmatamento no assentamento 26 de Março para os ano de 1990 e 2005.

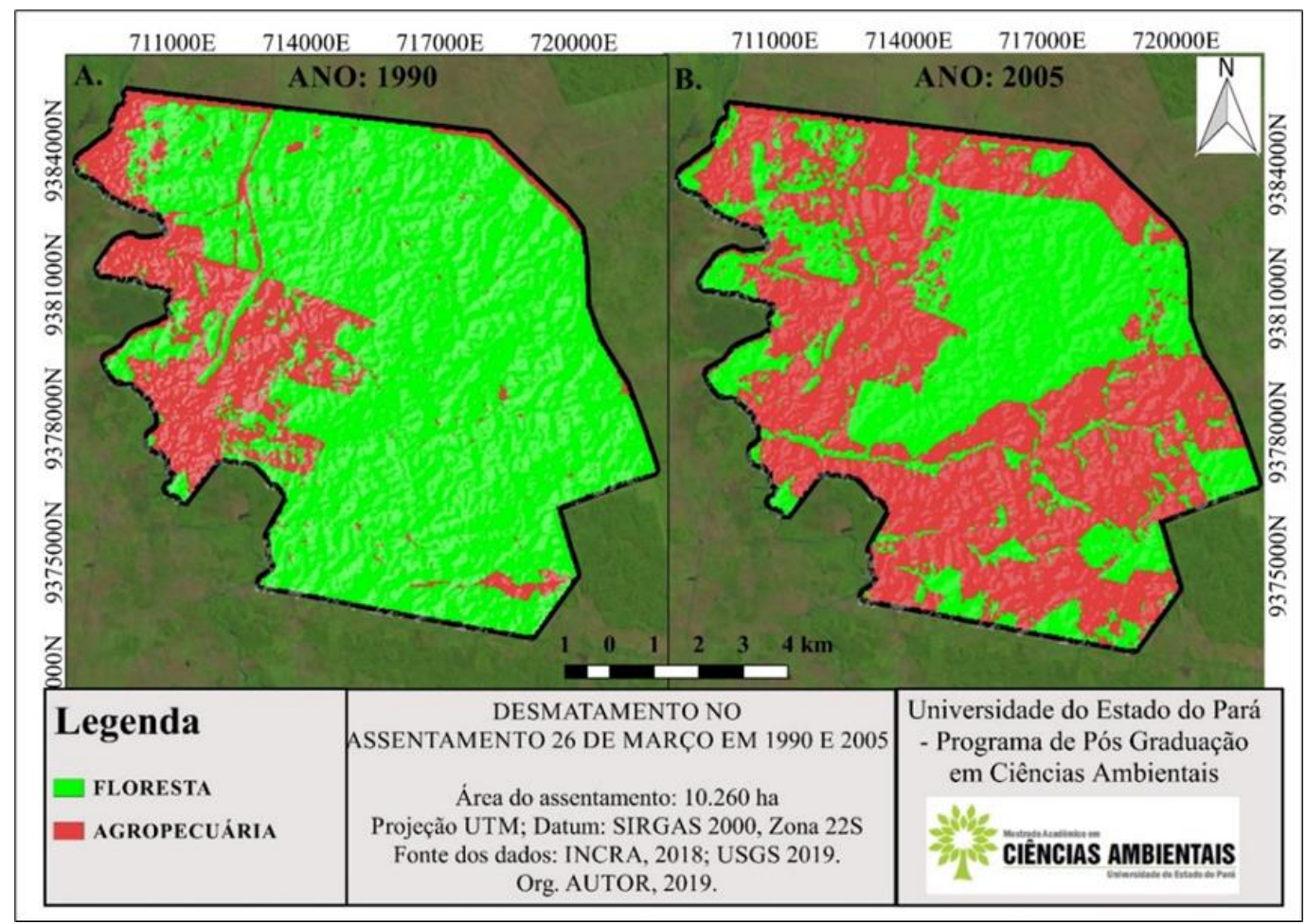

Fonte - Autor.

Na segunda metade do período avaliado, de 2005 a 2019, ocorre a criação oficial do assentamento, a mudança definitiva das famílias para o local e a consequente utilização das áreas de florestas pelos assentados como forma de conversão desses locais em áreas de cultivo. Segundo Neves e Schmitz (2018), os fatores que causaram ainda mais a diminuição das áreas de florestas no Projeto de Assentamento 26 de Março estão relacionados com o desmatamento para a extração e venda de madeira e para o estabelecimento de atividades relacionadas a agricultura e pecuária, como a implantação de pastagens e de cultivos.

Atualmente, a área destinada a agropecuária se constitui na maior classe de uso da terra do assentamento representando $68 \%$ do total da área (Figura 4). Vale ressaltar que a partir de 2008 , ano da criação oficial do assentamento, estão incluídas nessas classes, além da pastagem, outras formas de culturas agrícolas como as anuais, arroz (Oryza sativa), milho (Zea mays) e feijão (Phaseolus vulgaris); perenes, cupuaçu (Theobroma grandiflorum), açaí (Euterpe oleracea) e café (Coffea sp.); semiperenes, banana (Musa spp) e abacaxi (Ananas comosus) e policultivos que são usados para alimentação das famílias e venda do excedente.

De uma forma geral e de acordo com dados obtidos e espacializados nos mapas temáticos, ocorreu um significativo aumento do desmatamento no Projeto de Assentamento 26 de Março ao longo do período estudado, que perdeu aproximadamente 5.000 hectares de cobertura vegetal. Percebe-se que houve diminuição da área de floresta e aumento das atividades agropecuárias no período pesquisado (Figura 5). 
Em termos quantitativos, essa taxa representa cerca de $50 \%$ de floresta perdida e convertida para usos distintos.

Essa forma de uso dos recursos naturais no assentamento e a consequente transformação na paisagem são explicadas por diversos fatores que necessitam ser pensados de forma integrada e sistêmica. Pires (2016) contribui para esse entendimento quando afirma que nos assentamentos rurais existe grande dependência dos recursos paisagísticos naturais e carência de conhecimento dos tipos e dinâmica das paisagens para uma atividade agropecuária mais racional, com planejamento e gestão territorial das propriedades rurais.

Figura 4 - Mapa temático de desmatamento no Projeto de Assentamento 26 de Março para os ano de 2019.

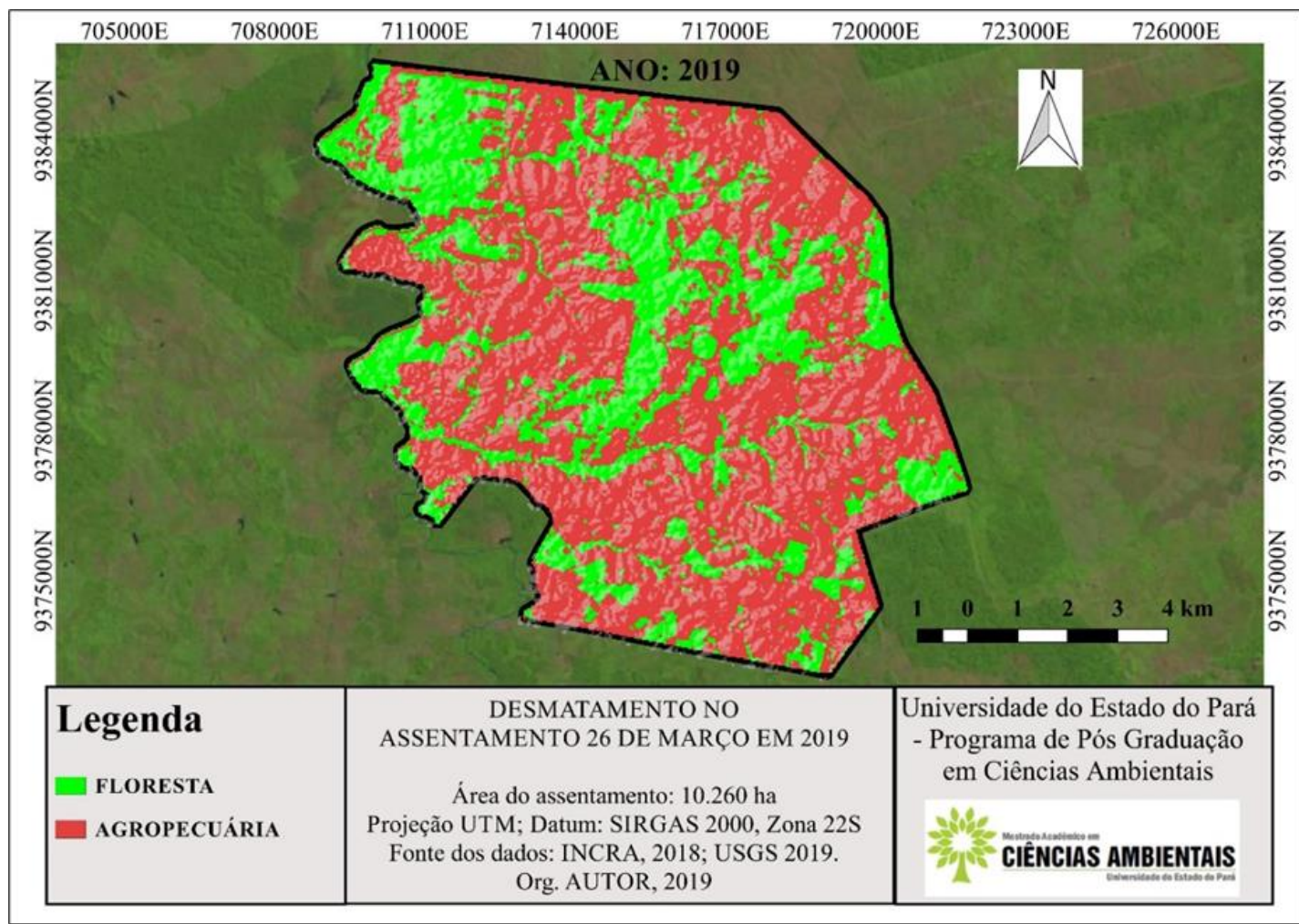

Fonte - Autor.

No contexto das classes de uso do solo no Sudeste Paraense, em muitas áreas a feição de maior evidência em termos de área corresponde às pastagens em seus diferentes estados, sendo que os principais vetores diretos de desmatamento dentro dos assentamentos nesse bioma são a pecuária extensiva e agricultura de corte e queima (ALENCAR et al., 2016).

Segundo Pereira et al. (2016), os sistemas de agricultores familiares no Sudeste Paraense, são focados na criação de animais, principalmente a bovinocultura, uma atividade que não é exigente em mão-de-obra, recebe crédito fácil e tem um mercado estável e logístico para sua produção, mas simultaneamente é uma atividade agrícola responsável pela maior parte do desmatamento na região, tal fato ocorre porque os pequenos agricultores consideram economicamente viável substituir a floresta e as antigas culturas agrícolas pela implantação de pastagens.

De acordo com Santos e Krajevski (2018), a criação de assentamentos rurais é envolto por uma grande discussão acerca de sua sustentabilidade, principalmente pelo contexto histórico, relação com a terra e pela sua natureza, que em maior ou menor medida produzem mudanças na estrutura fundiária, sendo possível observar modificações na economia regional, no meio ambiente, em aspectos sociais e políticos dos territórios onde se instalam. 
É importante mencionar também que os assentamentos rurais no Sudeste Paraense são em sua maioria implantados em antigas fazendas dedicadas à exploração da pecuária extensiva e por isso, com um grande passivo ambiental já instalado (BEDUSCHI FILHO, 2003), como é o caso do assentamento em estudo. Além disso, fatores importantíssimos como aptidão agrícola, topografia, drenagem, flora, fauna e presença de populações tradicionais não são levados em consideração na fase de planejamento. Assim o uso e a ocupação anteriores impõem aos assentados a herança de diversos problemas relacionados ao mau uso dos recursos naturais (PIRES, 2016).

Figura 5 - Dinâmica do desmatamento no Projeto de Assentamento 26 de Março entre 1990 e 2019.

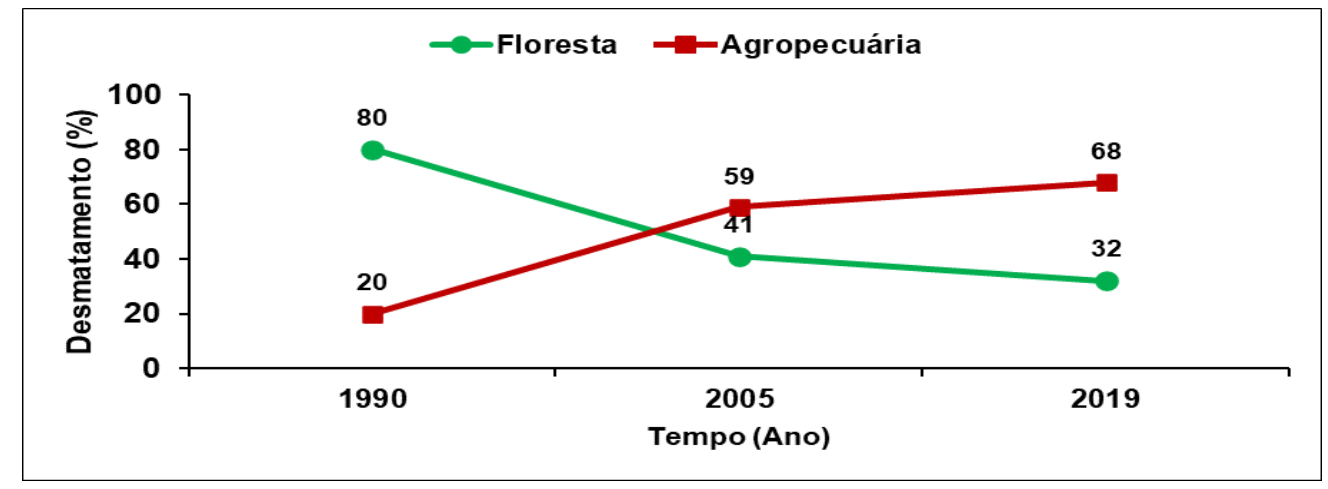

Fonte - Autor.

Castro e Watrin (2013), realizando uma análise espacial de áreas com restrição legal de uso do solo no Projeto de Assentamento 26 de Março com o uso de geotecnologias, chegaram a resultados que também apontam para um grande passivo ambiental instalado no local. As Áreas de Preservação Permanente e Reserva Legal estarem fora do que decreta a legislação, precisam ser revegetadas com espécies nativas do local ou que apresentem algum interesse imediato por parte dos assentados. Como proposta adicional para essa problemática identificada, os autores sugerem realização de estudos dos solos e da aptidão agrícola das terras, para implementar ações que visem à produção agrícola realizada em um planejamento de base.

Levando em consideração a questão do desmatamento em assentamentos de reforma agrária na Amazônia, Brandão Jr. e Souza Jr. (2011) sugerem três políticas públicas para melhor gestão ambiental dos mesmos: 1 - a Criação de novos assentamentos para fins agrícolas em áreas já desmatadas e degradadas. Neste contexto, os assentamentos criados não contribuirão para o avanço do desmatamento; 2 - recuperação das áreas degradadas, focando no reflorestamento e sistemas agroflorestais por meio de subsídios do programa Pronaf Florestal; e, 3 - como última proposta a inclusão dos assentamentos no programa governamental de monitoramento da Amazônia, ação que facilitaria o acompanhamento da aplicação das leis ambientais em áreas de assentamentos com o auxílio de geotecnologias.

Assim, percebe-se que o processo de transformação da paisagem no Projeto de Assentamento 26 de Março foi e ainda é influenciado de maneira direta pelas formas de uso da terra, fruto principalmente das políticas públicas pensadas para a região e das práticas agrícolas desempenhadas pelos assentados. Além disso, o contexto histórico de exploração da castanha na área onde hoje está inserido o assentamento e a posterior conversão desses locais em pastagens é fator essencial para entender o processo de mudança na paisagem, bem como sua estrutura atual.

O debate sobre o desmatamento em assentamentos no Sudeste Paraense é muito polêmico, uma vez que diversos autores afirmam que a criação de assentamentos aumenta significativamente o desflorestamento pela prática das atividades agropecuárias. Por outro lado, há as evidências de que as políticas públicas aplicadas na região amazônica nunca foram pensadas de forma sustentável. Aliado a isso está a falta de planejamento na fase de criação e implantação dos assentamentos, na escolha das áreas, que são selecionadas sem levar em consideração as características agronômicas do local e na própria educação ambiental por parte dos assentados que é deixada de lado (GAMA, 2016).

Os resultados relativos ao uso da terra no Projeto de Assentamento 26 de Março são preocupantes. Assim ressalta-se a importância do fortalecimento de políticas públicas adequadas à realidade local, bem 
como da realização de um planejamento focando nos remanescentes florestais e nas áreas já desmatadas, atendendo às necessidades e particularidades dos assentados. Além disso, considerar a melhoria da infraestrutura do assentamento e acesso aos mercados dos produtos agrícolas e florestais, além da geração e da disponibilização de alternativas produtivas por meio por meio dos resultados da pesquisa agropecuária desenvolvida para as características da região.

\section{CONSIDERAÇÕES FINAIS}

A utilização integrada de produtos e técnicas de sensoriamento remoto e de Sistemas de Informações Geográficas para análise da dinâmica do desmatamento no Projeto de Assentamento 26 de Março, mostrou-se eficiente para a integração de dados que foram essenciais para o entendimento do padrão de desmatamento existente no local. Isto possibilitou o cruzamento de informações que explicam a instalação e a evolução do cenário, além de contribuir nos processos de monitoramento, fiscalização de políticas de gestão territorial e de planejamento de ações de combate ao desmatamento.

$\mathrm{Na}$ análise dos resultados relativos à dinâmica do desmatamento, observa-se que desde 1990 o Projeto de Assentamento 26 de Março perdeu cerca de $50 \%$ de sua vegetação nativa. A redução das áreas de florestas está intimamente relacionada ao aumento das atividades agropecuárias, sendo estas últimas à classe dominante na paisagem atual do assentamento.

O desmatamento no referido assentamento é fruto do contexto histórico e agrário ocorrido no Sudeste Paraense, relacionando-se diretamente com o processo de exploração da castanha, com a política de reforma agrária executada na região, que possibilitou e intensificou a luta pela terra e com os incentivos fiscais que ajudaram a consolidar a pecuária como atividade predominante e um dos principais vetores do desmatamento no local.

Assim, os resultados revelam grandes taxas de desmatamento no assentamento estudado, no entanto, esse cenário não pode ser explicado com base em uma única causa, mas em uma combinação de fatores, dos quais se destacam: a ausência ou fragilidade de fiscalização e monitoramento, a assistência técnica e extensão rural inadequada e sem continuidade e a vulnerabilidade econômica dos assentados.

Além disso, essa forma de uso da terra é fruto dos diferentes manejos dos recursos naturais que tem reflexo direto na alteração da paisagem ao longo do tempo e na formação de um mosaico de unidades paisagísticas bem distintas dentro do mesmo espaço. Nesse sentido, as Áreas de Preservação Permanente e Reserva Legal degradadas necessitam ser recuperadas e os remanescentes vegetais devem ser conservados.

\section{REFERÊNCIAS}

AlencAR, A.; PEREIRA, C.; CASTRO, I.; CARDOSO, A.; SOUZA, L.; COSTA, R.; BENTES, A. J.; STELLA, O.; AZEVEDO, A.; GOMES, J.; NOVAES, R. Desmatamento nos assentamentos da Amazônia: histórico, tendências e oportunidades. Brasília - DF: IPAM, 93p. 2016.

ALENCAR, I. C. Produção do espaço agrário na Amazônia: Uma Interpretação geográfica do desmatamento no Projeto de Assentamento Bom Jardim, Pacajá - Pará. 2017. 124 f. Dissertação (Mestrado em Geografia) Instituto de Filosofia e Ciências Humanas, Universidade Federal do Pará, Belém - PA, 2017.

ALVES, L. da C.; BISPO, M. O. Estudos socioeconômicos e culturais das famílias do assentamento P.A. Zé Pereira, Município de Porto Nacional -TO. Revista Interface, Edição no 16. p. 18 - 30.2018.

ARAUJO, E. F. Tipologias Camponesas do Assentamento 26 de Março - PA: Desafios para o desenvolvimento. Marabá. 2008.

ÁVILA, S. R. S. A. de; ÁVILA, M.; BERNARDI, J. V. E.; COUTO JÚNIOR, A. F. Estudo exploratório sobre dinâmica do desmatamento em assentamentos localizados no território portal da Amazônia. Revista Retratos de Assentamentos. Vol. 22 N.1 de 2019. https://doi.org/10.25059/25272594/retratosdeassentamentos/2019.v22i1.330

BARREIROS, R. M. M.; FERNANDES, D. A.; ANDRADE, R. A.; AMARAL, G. S. A transição histórica

\begin{tabular}{|c|c|}
\hline Caminhos de Geografia & Uberlândia-MG \\
\hline
\end{tabular}


das oligarquias da castanha na região de Marabá: redes sociais, hegemonia e transformações no bloco de poder das elites locais entre os anos de 1920 e 1980. XII Congresso Brasileiro de História Econômica \& 13를 Conferência Internacional de História de Empresas. Niterói, agosto de 2017.

BARROS, C. J. O sonho se faz a mão e sem permissão: Escravidão temporária e reforma agrária no Sudeste do Pará. 2011. 251 f. Dissertação (Mestrado em Geografia). Universidade de São Paulo, São Paulo, 2011.

BEDUSCHI FILHO, L. C. Assentamentos rurais e conservação da natureza: Do estranhamento a ação coletiva. São Paulo: Iglu: FAPESP, 2003.

BITTENCOURT, G. A.; BIANCHINI, V. Agricultura familiar na região sul do Brasil. Consultoria UFT/ 036- FAO/ INCRA, 1996.

BRANDÃO JUNIOR, A.; SOUZA JUNIOR, C. Desmatamento nos assentamentos de reforma agrária na Amazônia. www.imazon.org.br Junho, № 7, 2006.

CARVALHO, T. S.; DOMINGUES, E. P. Projeção de um cenário econômico e de desmatamento para a Amazônia Legal brasileira entre 2006 e 2030. Nova economia. [online]. vol.26, n.2, pp.585-621. 2016. https://doi.org/10.1590/0103-6351/2665

CASTRO, A. R. da C.; WATRIN, O. dos S. Análise espacial de áreas com restrição de uso do solo em projeto de assentamento no Sudeste Paraense. Geografia Ensino \& Pesquisa, v.17, n. 2, p.157166, 2013. https://doi.org/10.5902/2236499410779

CÔRTES, J. C.; D'ANTONA, Á. de O. Dinâmicas no uso e cobertura da terra: perspectivas e desafios da Demografia. R. bras. Est. Pop., Rio de Janeiro, v. 31, n.1, p. 191-210, jan./jun. 2014. https://doi.org/10.1590/S0102-30982014000100011

EMATER - Empresa de Assistência Técnica e Extensão Rural do Estado do Pará. Plano de Desenvolvimento do Assentamento 26 de março / Empresa de Assistência Técnica e Extensão Rural do Estado do Pará. __ Marituba: EMATER, 2013. 177 p. il. P221p

EMMI, M. F. Os castanhais do Tocantins e a indústria extrativa no Pará até a década de 60, n. 166. Belém: UFPA/NAEA, 2002, p. 1-25.

FARIAS, M. H. C. S.; BELTRÃO, N. E. S.; SANTOS, C. A.; CORDEIRO, Y. E. M. Impacto dos assentamentos rurais no desmatamento da Amazônia. Mercator (Fortaleza), v. 17, 2018. https://doi.org/10.4215/rm2018.e17009

FARIAS, M. H. C. S.; BELTRÃO, N. E. S.; SANTOS, C. A.; SILVA, C. Potencial do Cadastro Ambiental Rural (CAR) no controle do desmatamento em assentamentos no município de Novo Repartimento (PA). Revista de Geografia e Ordenamento do Território (GOT), n. 14 (setembro). Centro de Estudos de Geografia e Ordenamento do Território, p. 179-199, 2018. https://doi.org/10.17127/got/2018.14.007

FREITAS, E. O. A Terra e os trabalhadores: Um estudo de caso sobre a Função social da propriedade. ANPUH - XXV Simpósio Nacional de História - Fortaleza, 2009.

GAMA, A. A. F. Desmatamento no Assentamento 26 de Março em Marabá: Em busca de alternativas agroecológicas aliadas à educação ambiental. 2016. 80 f. Dissertação (Mestrado em Dinâmicas Territoriais e Sociedade na Amazônia). Universidade Federal do Sul e Sudeste do Pará, Marabá, 2016.

HORA, K. E. R.; MAURO, R. A.; CALAÇA, M. Desafios para o parcelamento dos assentamentos de reforma agrária sob a perspectiva ambiental a partir da experiência do MST em Goiás. Revista NERA. Presidente Prudente v. 22, n. 49, pp. 140-167 Ma.-Ago./2019.

IBGE - Instituto Brasileiro de Geografia e Estatística. IBGE - cidades. 2020. Disponível em: https://cidades.ibge.gov.br/brasil/pa/maraba/panorama. Acessado em 28 de setembro de 2020. 
IFPA - Instituto Federal do Pará. Diagnóstico preliminar sócio, cultural e agroambiental do Projeto de Assentamento 26 de Março e da área do Campus Rural de Marabá. Marabá-PA: Mimeo, 2012.

INCRA - Instituto Nacional de Colonização e Reforma Agrária. Superintendência Regional Pará / Marabá - SR 27: Assentamentos - Informações Gerais. 2017. Disponível em: http://painel.incra.gov.br/sistemas/index.php. Acesso em: 07 de setembro de 2019.

INMET - instituto Nacional de Meteorologia. Dados Históricos. Ministério Da Agricultura, Pecuária E Abastecimento. Disponível em: http://www.inmet.gov.br/portal/. Acesso em: 09 de setembro de 2019.

INPE - Instituto Nacional de Pesquisas Espaciais. Sistema de Processamento de Informações Georreferenciadas (SPRING). 2017.2 Disponível em: http://www.dpi.inpe.br/spring/portugues/index.html. Acesso em: 03 de maio 2018.

JOANONI NETO, V.; GUIMARÃES NETO, R. B. Amazônia: Políticas governamentais, práticas de 'colonização' e controle do território na ditadura militar (1964-85). Anuário IEHS. Vol. 34, № 1, 99122, 2019.

LEAL, M.; MANIESI, V. Dinâmica de desflorestamento nos assentamentos extrativistas do município de Humaitá, Amazonas. Revista de Geografia e Ordenamento do Território (GOT); Porto Ed. 14: 251266. 2018. https://doi.org/10.17127/got/2018.14.010

LEITE, V. R.; PEDLOWSKI, M. A.; HADDAD, L. N. Assentamentos de reforma agrária como agentes de recuperação da cobertura vegetal em paisagens degradadas de Mata Atlântica na região norte fluminense. Revista NERA. Presidente Prudente Ano 17, no. 25 pp. 136-146 Jul-dez./2014.

LOEBMANN, D. G. S. W.; MAÇORANO, R. P.; SILVA, G. B. S.; VICENTE, L. E.; VICTORIA, D. C. Interpretação de alvos a partir de imagens de satélite de média resolução espacial. Circular TécnicaEMBRAPA/INPE. Campinas, SP Dezembro, 2012.

MACIEL, R. C. G.; LIMA JÚNIOR, F. B. de; SILVA, F. A. S.; BRITO, A. P. D.; CAVACANTE FILHO, P. G.; PENHA, D. de L. B. Inovação, reforma agrária e agricultura familiar: O caso da produção de palmito no Projeto de Desenvolvimento Sustentável Bonal. Cadernos de Ciência \& Tecnologia, Brasília, v. 31, n. 3, p. 493-522, set./dez. 2014.

MDA - Ministério do Desenvolvimento Social. Catálogo de produtos ofertados pela agricultura familiar. - Brasília, DF: Secretaria Nacional de Segurança Alimentar e Nutricional, 2018. 136 p. 2018.

MENGATTO JUNIOR, E. A.; DE OLIVEIRA, R. C.; SILVA, J. O município de Marabá, PA frente ao ZEE na Amazônia Legal: avaliação das taxas de desmatamento. In: Embrapa Informática Agropecuária-Artigo em anais de congresso (ALICE), 2017, Campinas. DOI 10.20396/sbgfa.v1i2017.2206 - ISBN 978-85-85369-16-3.

NASCIMENTO, C. P.; SILVA, M.; FERREIRA, M. B. P. A pecuária como atividade primaz na Amazônia: Uma discussão acerca dos seus aspectos ambientais, das populações humanas envolvidas e do papel das instituições na dinâmica desta atividade. | Revista de Estudos Sociais. N. 33, V. 17, Pag. 208. 2015. https://doi.org/10.19093/res.v17i33.2238

NEVES, E. C. C.; SCHMITZ, H. Meio século de oligarquia, uma década de assentamento: a herança da Fazenda Cabaceiras no Assentamento 26 de Março, em Marabá-PA. Estudos Sociedade e Agricultura: 148-171, 2018. https://doi.org/10.36920/esa-v26n1-7

OLIVEIRA, M. G. de C.; PEREIRA, R. M. Importância da mecanização na agricultura familiar brasileira. Empresa Brasileira de Pesquisa Agropecuária, 2010.

PEREIRA, F. M. "A ousadia de conviver com a floresta" uma ecologia política do extrativismo na Amazônia. Tese de Doutoramento em Democracia no Século XXI, apresentada à Faculdade de Economia da Universidade de Coimbra, Coimbra, 2015.PEREIRA, João Márcio Mendes. Estado e mercado na reforma agrária brasileira (1988-2002). Estud. hist. (Rio J.) vol.28 no.56 Rio de Janeiro 
jul./dez. 2015. https://doi.org/10.1590/S0103-21862015000200009

PEREIRA, R.; SIMMONS, C.; WALKER, R. S. Agrarian Reform, and Globalization in the Brazilian Amazon: Cattle versus the Environment. Land. 2016, 5, 24. https://doi.org/10.3390/land5030024

PINTO, J. F. S. K. C. Dinâmica do uso e da cobertura da terra das áreas queimadas no Município de Marabá (PA). 2016. 116 f. Dissertação (Mestrado em Ciências Ambientais) Programa de PósGraduação do Instituto de Geociências, Universidade Federal do Pará em convênio com EMBRAPAAmazônia Oriental, INPE-CRA e Museu Paraense Emílio Goeldi. BELÉM-PA, 2016.

PIRES, M. E. R. Caracterização e dinâmica socioambiental dos geossistemas no Assentamento Fazenda Esperança, em Rondonópolis, Mato Grosso. 2016. 135 f. Dissertação (Mestrado em Geografia). Universidade Federal de Mato Grosso, Rondonópolis, 2016.

SAMPAIO, S. M. N.; VENTURIERI, A.; DA SILVA, B. N. R.; SILVA, L. G. T.; HOMMA, A. K. O.; CARVALHO, R. A. Dinâmica da cobertura vegetal e uso da terra no Sudeste Paraense: O caso do projeto de assentamento São Francisco. Belém: Embrapa Amazônia Oriental, 38p. Documentos, 159, 2003.

SANGALLI, A. R.; SCHLINDWEIN, M. M.; CAMILO, L. R. Produção e geração de renda na agricultura familiar: um diagnóstico do assentamento rural Lagoa Grande em Dourados, Mato Grosso do Sul. Ciência e Natura, v. 36 n. 2, mai-ago. p. 180 -192. 2014. https://doi.org/10.5902/2179460X11064

SANTOS, C. S.; KRAJEVSKI, L. C. Assentamentos rurais e as modificações socioeconômicas no município de Rio Bonito do Iguaçu. Revista NERA. Presidente Prudente, ano 21, n. 41, pp. 39-61 Jan.-Abr./2018.

SCOLES, R.; CANTO, M. S.; ALMEIDA, R. G.; VIEIRA, D. P. Sobrevivência e Frutificação de Bertholletia excelsa Bonpl. em Áreas Desmatadas em Oriximiná, Pará. Revista Floresta e Ambiente. 2016, vol.23, n.4, pp.555-564. https://doi.org/10.1590/2179-8087.132015

SOARES, J. L. N.; ESPINDOLA, C. R. Geotecnologias no planejamento de assentamentos rurais: premissa para o desenvolvimento rural sustentável. Revista Nera. ISSN: 1806-6755, Vol. 11, N. 12, 2008.

TRINDADE JÚNIOR, S-C. C. da; MADEIRA, W. do V. Polos, eixos e zonas: Cidades e ordenamento territorial na Amazônia. PRACS: Revista Eletrônica de Humanidades do Curso de Ciências Sociais da UNIFAP. 2016;9(1):37-54. 2016. https://doi.org/10.18468/pracs.2016v9n1.p37-54

VARANDA, T. S.; EVANGELISTA, J. O.; MESQUITA, S. A. J.; COSTA, J. B. Análise multitemporal da cobertura vegetal do projeto de assentamento Piquiá no município de Marabá- PA. Revista Geoaraguaia. ISSN:2236-9, Barra do Garças -MTv.8, n.3, p.53-78. Dezembro 2018.

VIEIRA, I. C. G.; SANTOS JUNIOR, R. A. O.; TOLEDO, P. M. de. Dinâmicas produtivas, transformações no uso da terra e sustentabilidade na Amazônia. Um olhar territorial para o desenvolvimento da Amazônia, 1st edn. BNDES, Rio de Janeiro, p. 370-395, 2014.

YANAI, A. M.; NOGUEIRA, E. M.; GRAÇAS, P. M. L. de A.; FEARNSIDE, P. M. Deforestation and Carbon Stock Loss in Brazil's Amazonian Settlements Aurora Miho Yanai. Environmental Management. 59:393-409. 2017. https://doi.org/10.1007/s00267-016-0783-2

ZAMBONIN, R. V.; SOUZA, V.; BESERRA NETA, L. C.; SOARES JÚNIOR, S. T. Mudança na paisagem no Assentamento Chidauá. ACTA Geográfica, Boa Vista, v.11, n.27, set./dez. pp.109-125, 2017.

Recebido em: 09/11/2019

Aceito para publicação em: 28/09/2020 